\title{
THE EDITORIAL PENCIL MOVES WEST
}

$\mathrm{A}$ $s$ you have no doubt noticed from the inside cover, this issue of Latin American Antiquity marks the third change in editorship since the journal's inception in 1990. During the terms of its first two editors, Prudence M. Rice (1990-93) and David M. Pendergast (1993-96), the journal established itself firmly in the world of archaeological publishing. And under my immediate predecessors, coeditors Gary M. Feinman and Linda Manzanilla, it has attained world-class standing and recognition. It has more than met the expectations of the Board of Directors of the Society for American Archaeology that originally created Latin American Antiquity a decade ago.

Coeditors Feinman and Manzanilla, along with their editorial assistants, Susan Kepecs and Linda M. Nicholas, have set a series of high standards that the new editorial office will strive to maintain. I would like to take this opportunity to point out to the readership some of the accomplishments of the team that is now stepping down. In the first place, the journal regularly appears in your mailboxes during (or very close to) the same month that is printed on the cover. This was no mean feat. Gary and Linda established a practice of making a decision on all papers within four to six months of submission, and nearly always were able to communicate decisions to authors in an even shorter period of time. One of my first goals will therefore be to try to maintain the same speed and efficiency.

In the second place, the rate of submissions to the journal and the resulting quality of the articles has also improved over the lifespan of the journal. Certainly this is due in part to the increasing acceptance of the journal within the archaeological community. But certainly it is also due to the high editorial standards of both my distant and, especially, my immediate predecessors. They have set and maintained a high editorial standard, one that $I$ hope to continue in practice.

In the third place, Feinman and Manzanilla were able to expand the scope of the journal, and increase the participation of our Latin American colleagues. They created a long-needed style guide for Spanishlanguage submissions, to parallel the existing one for English manuscripts. More importantly, they expanded the scope of the Board of Editors and the Editorial Advisory Committee to include speakers of English, Spanish, and Portuguese. I applaud this policy, and have endeavored to maintain it in the newly constituted committees.

The previous editorial team also made one important change to the editorship of Latin American Antiquity: the creation of the coeditorship, shared between a North American and a Latin American archaeologist. We are actively striving to continue this practice into the current editorial term. Although at press time we had not been able to name a Latin American coeditor, I trust that by the time you read this, and certainly by your receipt of the next issue, we will have a Latin American colleague sharing the helm. I thank the Committee on the Americas, and its chair, Luis Alberto Borrero, for their efforts and advice in this regard.

I should also point out that, although the names on the masthead have changed, the process of transition between editorial offices is not nearly so abrupt. As the Society's stewardship model was explained to me last year by President Vin Steponaitis, each editor shepherds the journal's review process during his or her term of office, regardless of whose name appears on the masthead. Therefore, given that the contents of this issue were prepared some months before I actually assumed the editorship, all the articles you will read in it were seen through the entire review process by coeditors Feinman and Manzanilla. And in the next 
couple of issues you will find a mix of articles shepherded through the process by both the old and the new editorial teams. We have effected a very smooth transition this year, and I hope it will serve as a model for future transitions.

One major change you will be seeing in this and upcoming issues is an increased number of pages in each issue. The Board of Directors of the SAA has authorized an increase of an average of 16 pages per issue for Volume 10, on the recommendation of the Publications Committee, chaired by Christopher Chippindale. This will bring the physical size of the journal more in line with the expectations of the profession. And we anticipate the possibility of even greater increases in the future.

You also will notice one slight difference on the inside back page, under the Notice to Authors. We now specifically solicit not only articles whose data content falls geographically within Latin America, but we are also encouraging articles that are primarily theoretical or methodological in focus, if that focus has relevance to the archaeology of Latin America. Latin American Antiquity is more than just a regional journal, and as an organ of the Society for American Archaeology it should also reflect the broader interests of its readership.

As Latin American Antiquity approaches the end of its first decade of publication, we also plan to prepare a 10-year cumulative index that will be published in Volume 10, number 4 . I trust it will be only the first of many.

I must acknowledge the mostly volunteered efforts of so many people who have helped ease the transition to the new editorial offices. In the first place, Gary Feinman has endured long phone calls and emails, and patiently answered all of my questions. Susan Kepecs and Linda Nicholas of his Wisconsin editorial staff have provided detailed summaries and formats for keeping all the myriad records involved in tracking manuscripts through the review process. Without their well-developed systems, and their willingness to share them, we would have been weeks behind right at the start. Christina Conlee, my editorial assistant in Santa Barbara, has done a superhuman job of getting the physical office set up, and the review process smoothly underway. Inmaculada López Bueis and Johny Isla Cuadrado have helped set up the Spanish-language files and correspondence. UCSB College of Letters and Science Provost Zimmerman and Social Science Dean Donnerstein have provided substantial funding for the new editorial office. The Department of Anthropology, UCSB, has provided both office space and computer support. And the anthropology office staff has put together the financial accounting systems for the journal, and helped with establishing the physical office. We gratefully acknowledge all these sources of support.

Finally, I wish to encourage your submissions of future articles and your suggestions for future directions of Latin American Antiquity. It is your journal.

KATHARINA J. SCHREIBER Editor

Note: Due to a technical problem, figures 7 and 8 in Jo Ann F. Pratt's report, "Determining the Function of One of the New World's Earliest Pottery Assemblages: The Case of San Jacinto, Colombia," in Latin American Antiquity 10:79, did not reproduce properly. We print the correct figures on the following pages and apologize for the error. 